\title{
Molecular phylogeny and phylogeography of the Cuban cave-fishes of the genus Lucifuga: Evidence for cryptic allopatric diversity
}

\author{
Erik García-Machado a , Damir Hernández ${ }^{a}$, Alfredo García-Debrás ${ }^{\mathrm{b}}$, Pedro Chevalier-Monteagudo ${ }^{\mathrm{c}}$, \\ Cushla Metcalfe $^{\mathrm{d}}$, Louis Bernatchez ${ }^{\mathrm{e}}$, Didier Casane ${ }^{\mathrm{f}, *}$ \\ ${ }^{a}$ Centro de Investigaciones Marinas, Universidad de la Habana, Calle 16, No. 114 entre 1ra y 3ra, Miramar, Playa, Ciudad Habana 11300, Cuba \\ ${ }^{\mathrm{b}}$ Cuban Society of Zoology, Cuba \\ ${ }^{c}$ Acuario Nacional de Cuba, Calle 60, Miramar, Playa, Ciudad Habana 11300, Cuba \\ ${ }^{\mathrm{d}}$ Instituto de Biociências, Universidade de São Paulo, Rua do Matão 277, Cidade Universitária, Sao Paulo, Brazil \\ e Institut de Biologie Intégrative et des Systèmes (IBIS), Pavillon Charles-Eugène Marchand, Université Laval, Quebec QC, Canada G1K 7P4 \\ ${ }^{\mathrm{f}}$ Laboratoire Evolution Génomes et Spéciation, UPR 9034 CNRS and Université Paris Diderot - Paris 7, 1 Avenue de la Terrasse, 91198 Gif-sur-Yvette, France
}

\section{A R T I C L E I N F O}

\section{Article history:}

Received 16 March 2011

Revised 17 June 2011

Accepted 19 June 2011

Available online 30 June 2011

\section{Keywords:}

Blind cave fish

Cryptic species

Phylogeny

Phylogeography

Stygobiotic

\begin{abstract}
A B S T R A C T
Underground environments are increasingly recognized as reservoirs of faunal diversity. Extreme environmental conditions and limited dispersal ability of underground organisms have been acknowledged as important factors promoting divergence between species and conspecific populations. However, in many instances, there is no correlation between genetic divergence and morphological differentiation. Lucifuga Poey is a stygobiotic fish genus that lives in Cuban and Bahamian caves. In Cuba, it offers a unique opportunity to study the influence of habitat fragmentation on the genetic divergence of stygobiotic species and populations. The genus includes four species and one morphological variant that have contrasting geographical distributions. In this study, we first performed a molecular phylogenetic analysis of the Lucifuga Cuban species using mitochondrial and nuclear markers. The mitochondrial phylogeny revealed three deeply divergent clades that were supported by nuclear and morphological characters. Within two of these main clades, we identified five lineages that are candidate cryptic species and a taxonomical synonymy between Lucifuga subterranea and Lucifuga teresinarum. Secondly, phylogeographic analysis using a fragment of the cytochrome $b$ gene was performed for Lucifuga dentata, the most widely distributed species. We found strong geographical organization of the haplotype clades at different geographic scales that can be explained by episodes of dispersal and population expansion followed by population fragmentation and restricted gene flow. At a larger temporal scale, these processes could also explain the diversification and the distribution of the different species.
\end{abstract}

(c) 2011 Elsevier Inc. All rights reserved.

\section{Introduction}

The fragmented structure of groundwater aquifers, historical hydrogeological processes, and the reduced dispersal ability of organisms within these aquifers have produced a rich underground fauna characterized, in most cases, by highly structured populations and species with very restricted distributions (Lefébure et al., 2006; Culver and Pipan, 2009; Zakšek et al., 2009). Notably, phenotypes previously thought to occupy vast regions are, in fact, complexes of species that are geographically restricted. Recently, Culver et al. (2009) suggested that a trade off between vicariant and dispersal process may have acted to produce such patterns. Extreme environments like underground ecosystems may be particularly prone to producing cryptic speciation (Lefébure et al., 2006).

\footnotetext{
* Corresponding author. Fax: +3316982 3736 .

E-mail address: didier.casane@legs.cnrs-gif.fr (D. Casane).
}

Limited dispersal ability leading to strong isolation together with the severe environmental extremes, in terms of physical and ecological characteristics, may lead to diverging populations and ultimately to speciation without appreciable phenotypic changes. Stabilizing selection, reducing or eliminating morphological divergence, associated with the effects of genetic drift on small and isolated populations may thus be a mechanism producing cryptic diversity (Bickford et al., 2007).

Molecular data and the availability of new analysis methods have facilitated the discovery of cryptic diversity (DeSalle et al., 2005) and there are many examples from different groups of stygobiont invertebrates (Leys et al., 2003; Buhay and Crandall, 2005; Lefébure et al., 2006, 2007; Lejeusne and Chevaldonné, 2006; Finston et al., 2007; Page et al., 2008; Bradford et al., 2009; Guzik et al., 2009; Murphy et al., 2009; Trontelj et al., 2009; Zakšek et al., 2009). Although much has been done on the taxonomy, ecology and biology of subterranean fishes (Romero, 2001), few studies 
have been dedicated to analysing the structure of genetic diversity within species and the evolutionary relationships among species (Avise and Selander, 1972; Mitchell et al., 1977; Wilkens, 1988; Pérez and Moodie, 1993; Espinasa and Borowsky, 2000, 2001; Borowsky and Mertz, 2001; Borowsky and Vidthayanon, 2001; Dowling et al., 2002; Strecker et al., 2003; Wilkens and Strecker, 2003; Xiao et al., 2005; Colli et al., 2009). Most of these studies have been on Astyanax mexicanus, where strongly genetically structured populations have been identified (e.g. Strecker et al., 2003). One interesting case is the relatively poorly studied group of groundwater-dwelling fishes known as Lucifuga Poey that inhabit caves and sinkholes of Cuba and the Bahamas. This genus is one of the most diverse stygobiotic fishes described thus far (Romero, 2001). The distribution of the Lucifuga species in Cuba is highly patchy and is mostly restricted to coastal fringes and the exposed karstic plains of the west part of the island that contain phreatic, relatively stable, waters. The karstic rocks, representing about the $60 \%$ of the dry land, are not a homogeneous structure and different regions are recognized, depending on the composition of different types of karst and non-karstic rocks (Nuñez-Jiménez, 1967).

The Lucifuga are marine in origin and belong to the order Ophidiiformes (Nielsen et al., 1999). At present, seven species are recognized: four of them identified from Cuban fresh and brackishwater caves and sinkholes, Lucifuga subterranea (Poey, 1858), Lucifuga dentata (Poey, 1858), Lucifuga simile (Nalbant, 1981) and Lucifuga teresinarum (Díaz, 1988); two from brackish water sinkholes in the Bahamian Islands Lucifuga speleotes (Cohen and Robins, 1970) and Lucifuga lucayana (Møller et al., 2006) and one, Lucifuga inopinata (Cohen and McCosker, 1998), has been described from offshore Galapagos Islands, whose designation as Lucifuga remains doubtful (Cohen, personal communication). In addition, a variety of $L$. dentata, $L$. dentata var. holguinensis, was originally described from a single locality at the north eastern part of Cuba (Díaz et al., 1987a), however morphologically similar fishes have been also found at other distant localities in the middle south and western parts of the Cuban island (García-Debrás et al., 1999).

Díaz (1988) and Møller et al. (2006) identified a number of characters (e.g. caudal finray numbers, vertebrae number, and eye diameter) that distinguish Bahamian and Cuban species. However, the mosaic distribution of morphological characters within species makes Lucifuga taxonomy difficult, and also calls into question the taxonomical usefulness of some of these morphological characters (Nalbant, 1981; Díaz, 1988; Møller et al., 2006).

The only attempt to reconstruct the evolutionary pathways of Lucifuga spp. was conducted by Vergara (1980). He analysed 25 morphological characters from the three species described at that time (i.e. $L$. dentata, $L$. speleotes and $L$. subterranea), and two species of the genus Calamopteryx as outgroup. Vergara determined plesiomorphic and apomorphic character states and proposed that the Bahamas and Cuba harbour two different evolutionary lineages. He concluded that $L$. speleotes had a higher number of plesiomorphic character states that occurred early during Lucifuga evolution whereas L. subterranea is the most "adapted" species to underground environments (e.g. smallest eye-balls, lack of palatine teeth, smallest size, lower number of finrays, and a slender body shape). This view remained mostly unchanged until recently, when Møller et al. (2006) suggested that some aspects of Lucifuga taxonomy should be reconsidered. These authors proposed that the two subgenera Lucifuga and Stygicola are invalid, which are defined respectively, by the absence and presence of palatine teeth, and suggested that the lack of palatine teeth in L. subterranea and $L$. lucayana is homoplasious.

Given the observed trends from other stygobiotic organisms that are unable to disperse over long distances and that have putatively small effective population sizes, we hypothesize that Lucifu$g a$ is more diverse than recognized at present. One would expect: (a) relatively deep molecular divergences between morphological recognized species; (b) the occurrence of cryptic diversity in geographically restricted lineages; and (c) deep mitochondrial DNA differentiation between geographically distributed populations characterized by long internal branches connecting geographically restricted haplotypes. In this context, we examined molecular and morphological patterns of Lucifuga in Cuba. To maximize our chances of detecting most of the variation within Lucifuga, we sampled widely throughout its distribution in Cuba. Using mitochondrial and nuclear DNA sequences from several different loci, we first evaluated the phylogenetic relationships between the known species. We also investigated the phylogeographic patterns within the single most widely distributed species in order to identify possible mechanisms that may have operated historically to shape the present patterns of haplotype distribution. We also re-examined morphological variation in the light of the resulting inferred phylogenetic relationships.

\section{Materials and methods}

\subsection{Samples and localities}

We sampled Lucifuga throughout its distribution in Cuba, from the most eastern locality (Gibara, Holguín province) to Guanahacabibes at the West. Here we report for first time the occurrence of the genus Lucifuga outside the mainland in the Cuban archipelago. Five individuals, captured at a new locality, an unnamed crevice at Coco Key, were included in the analysis (Fig. 1, Table 1). Individuals of two of the nominal species (L. simile and $L$. teresinarum) were sampled at type localities (Table 1 ). The fishes were collected by scuba diving using hand nets and transported to the laboratory where they were identified following Nielsen et al. (1999) and original descriptions (Poey, 1858; Cohen and Robins, 1970; Nalbant, 1981; Díaz, 1988; Møller et al., 2006). Type specimens were available for L. teresinarum Díaz, 1988 (Holotype, MFP 2015 (reassigned as MFP 18.000385), male, and Paratype, MFP 2016 (reassigned as MFP 18.000386), male, Felipe Poey Museum, Faculty of Biology, University of Havana) and L. dentata var. holguinensis (no type designation, MFP 18.000420).

Small sections of muscle ( $\sim 50 \mathrm{mg}$ ) or fin clips were dissected from fresh samples and preserved in $95 \%$ ethanol. Whole fish were preserved in buffered formalin or $99 \%$ ethanol and later transferred to $70 \%$ ethanol. For localities where access was difficult or where no fish were found, older tissue samples that had been either frozen or preserved in ethanol were used (Table 1). Each fish was identified by a voucher with species name, and date of collection and locality, and stored in the Felipe Poey Museum (MFP) collection at the University of Havana (Table 1).

\subsection{Molecular methods}

For old tissue samples, DNA was extracted using the DNAeasy tissue kit (QIAGEN) following supplier guidelines. Fresh tissue, fin or muscle, was digested with proteinase $\mathrm{K}(100 \mu \mathrm{g} / \mathrm{mL})$ in $200 \mu \mathrm{L}$ lysis buffer (100 mM Tris-HCl, pH 8.0, 10 mM EDTA, $100 \mathrm{mM} \mathrm{NaCl}$, $0.1 \% \mathrm{SDS}$, and $50 \mathrm{mM}$ DTT) at $50{ }^{\circ} \mathrm{C}$ with slow constant shaking, followed by a phenol: chloroform extraction and purification using a Phase Lock Gel ${ }^{\mathrm{TM}}$ (Eppendorf).

The polymerase chain reaction (PCR) was used to amplify a total of $1982 \mathrm{bp}$ (aligned positions) of the mitochondrial DNA (mtDNA) genome, including the complete sequence for the ATP8 and ND4L genes, and partial sequences of cytochrome $b(c y t b)$, tRNA $^{\mathrm{Arg}}$, tRNA ${ }^{\text {Lys }}$, ATP6, and ND2. We also amplified partial sequence of the visual pigment rhodopsin gene (Rhod) (373 bp) and the first intron of a homeobox-containing gene (evx1) (564 bp). For a selected 


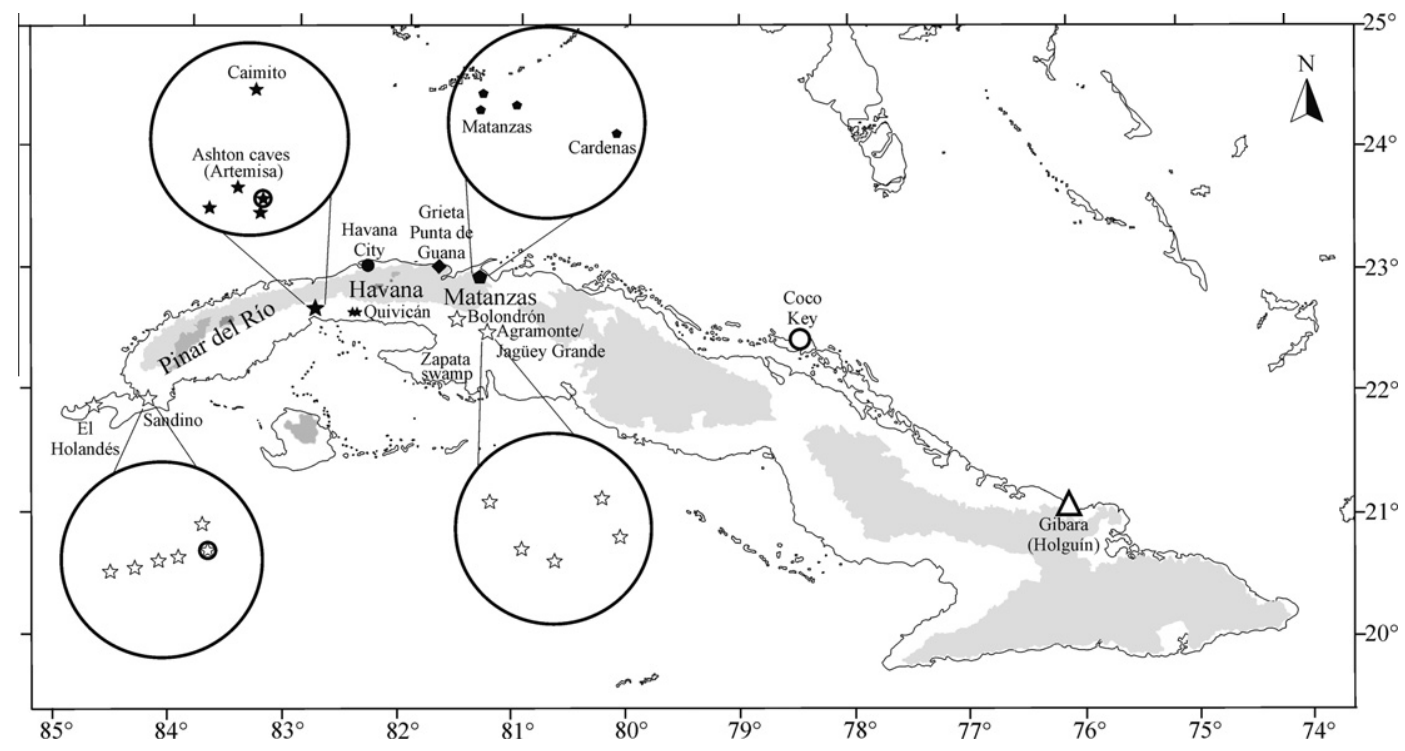

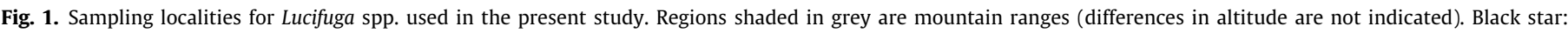

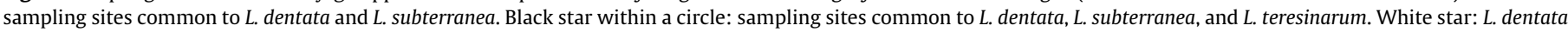

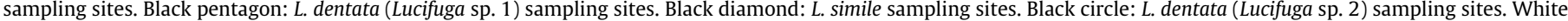

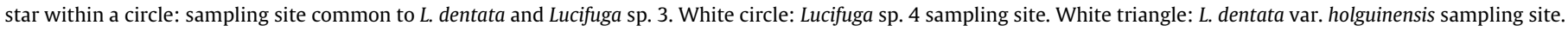

subsample, sequences of two other nuclear genes [calmodulin intron $4(C A M-4)$ and S7 ribosomal protein intron 1(S7-1)] were obtained (Table 1 ).

Total genomic DNA, 5-100 ng, was used as template in a $50 \mu \mathrm{L}$ PCR reaction with two units of GoTaq DNA polymerase (Promega), $0.2 \mu \mathrm{M}$ of each primer, $0.2 \mu \mathrm{M}$ of dNTPs, and $1.5 \mathrm{mM} \mathrm{MgCl}_{2}$. The primer sequences and the amplification conditions can be obtained by request to the authors (Supplementary material 1).

PCR products were purified using the QIAquick ${ }^{\circledR}$ PCR purification kit (QIAGEN) and cycle-sequenced in both directions using the Big Dye terminator sequencing kit (Applied Biosystems). The fragments were resolved with an $\mathrm{ABI} 3100$ automated sequencer (Applied Biosystems). For $e v x 1$ and for poorly amplified fragments, PCR products were cloned using the pGEM-T Easy Vector System (Promega). Plasmids were purified using Wizard Plus Minipreps DNA Purification System (Promega). Two to three clones were sequenced per sample using T7 and SP6 primers. Sequences were deposited in the EMBL database and accession numbers are provided in Table 1.

\subsection{Sequence analysis and phylogeny reconstruction}

Sequences were edited using Bioedit Sequence Alignment Editor v5.0.9 (Hall, 1999), and inspected by eye against the original chromatogram. Most alignments were straightforward and did not required further handling, but when necessary multiple sequence alignments were performed with Clustal W (Thompson et al., 1994) as included in MEGA version 4 (Tamura et al., 2007). Secondary structure of the partial tRNA gene sequence ( $t R N A^{\text {Lys }}$ ) was inferred to identify homologous sequence positions. The separate gene segments were concatenated in a single alignment using MEGA version 4 (Tamura et al., 2007).

Selection of the outgroups was based on a number of considerations. First, there are relatively limited sequences from this order of fishes in sequence data banks making difficult to test a priori the best candidates as outgroups. Second, as the group lacks strong phylogenetic analysis, the hypothetical sister taxon of Lucifuga is unknown at present. We therefore used homologous mtDNA sequences from four Ophidiiformes [Bassozetus zenkevitchi (accession number NC004374.1), Cataetix rubrirostris (accession number AP004407.1), Diplacanthopoma brachysoma (accession number AP004408.1) and Lamprogrammus niger (accession number AP004410.1)] reported by Miya et al. (2003). Two species C. rubrirostris and $D$. brachysoma are both of the same subfamily (Bythitinae) of Lucifuga. In addition we generated new sequence from a fifth species Stygnobrotula latebricola, also from the subfamily Bythitinae.

The model of nucleotide substitution best fitting the data was selected using the Bayesian information criterion (BIC; Schwarz, 1978) as implemented in jModelTest version 0.1.1 (Guindon and Gascuel, 2003; Posada, 2008).

We used neighbour joining (NJ), maximum likelihood (ML), and Bayesian methods to generate phylogenetic trees. NJ trees were constructed using MEGA version 4 (Tamura et al., 2007). PhyML 2.4.4 (Guindon and Gascuel, 2003) and MrBayes 3.1.2 (Ronquist and Huelsenbeck, 2003) were used to infer the ML and Bayesian consensus trees respectively. A priori selected model parameters (see above) such as nucleotide substitution matrix and gamma-distributed rate variation across sites were used for tree inference. Stationary base frequencies and substitution rates were optimized during tree inference. The Bayesian analyses consisted of two independent runs using four Metropolis coupled Monte Carlo Markov chains for $1.3 \times 10^{6}$ generations and sampling trees every 100 generations. The first $20 \%$ of sampled trees was discarded as burn-in.

For NJ and ML trees, the robustness of the nodes was assessed using the bootstrap method with 1000 and 100 replicates, respectively. Support for the Bayesian analysis was obtained from posterior probabilities of the nodes in the consensus tree.

\subsection{Population aggregation analysis of the nuclear sequence variation}

Here we proceeded essentially as described by Davis and Nixon (1992). Variable nucleotide site positions were first analyzed among individuals from a single locality assuming that they belonged to the same species, and those populations sharing the same character states were considered conspecific. Groups of populations showing different nucleotide diagnostic profiles were then considered to belong to different evolutionary lineages. We did not establish cutoff levels for polymorphic characters as suggested by 
Table 1

Specimens used in the study, identification and accession numbers of the analyzed data sets.

\begin{tabular}{|c|c|c|c|c|c|c|c|c|c|c|c|}
\hline \multirow[t]{2}{*}{ Species } & \multirow{2}{*}{$\begin{array}{l}\text { New taxonomical } \\
\text { partitions }\end{array}$} & \multirow{2}{*}{$\begin{array}{l}\text { Sample } \\
\text { identification }\end{array}$} & \multirow{2}{*}{$\begin{array}{l}\text { Voucher } \\
\text { (MFP18) }^{\text {a }}\end{array}$} & \multirow{2}{*}{$\begin{array}{l}\text { Collection locality } \\
\text { (cave, municipality) }\end{array}$} & \multirow[t]{2}{*}{$\mathrm{mtDNA}^{\mathrm{b}}$} & \multirow[t]{2}{*}{$c y t b^{c}$} & \multicolumn{5}{|c|}{ Nuclear genes } \\
\hline & & & & & & & Rhod & evx1 & CAM-4 & $S 7-1$ & Iso $^{d}$ \\
\hline \multirow[t]{53}{*}{ Lucifuga dentata } & Lucifuga dentata & Ld1Emi & 000340 & Emilio, Artemisa & FR717320 & FR716705 & FR750229 & FR734114 & & & $\mathrm{X}$ \\
\hline & & & & & FR717870 & & FR750231 & & & & \\
\hline & & & & & FR718820 & & & & & & \\
\hline & & Ld3Lec & 000345 & La Lechuza, Artemisa & FR717321 & FR716707 & FR750229 & FR734125 & & & $\mathrm{x}$ \\
\hline & & & & & FR717870 & & & & & & \\
\hline & & & & & FR718823 & & & & & & \\
\hline & & Ld20Sit & NV & El Sitio, Artemisa ${ }^{g}$ & FR717320 & FR716705 & FR750229 & FR734115 & & & $\mathrm{x}$ \\
\hline & & & & & FR717870 & & FR750231 & FR734116 & & & \\
\hline & & & & & FR718820 & & & & & & \\
\hline & & Ld21Ban & 000343 & Baño2, Artemisa & FR717320 & FR716700 & FR750229 & FR734110 & & & $\mathrm{x}$ \\
\hline & & & & & FR717870 & & FR750231 & & & & \\
\hline & & & & & FR718821 & & & & & & \\
\hline & & Ld27Emi & 000340 & Emilio, Artemisa & FR717320 & FR716702 & FR750229 & FR734110 & & & $\mathrm{x}$ \\
\hline & & & & & FR717870 & & & & & & \\
\hline & & & & & FR718822 & & & & & & \\
\hline & & Ld33Fel & 000320 & Felipe, Sandino & FR717318 & FR716690 & FR750229 & FR734108 & & & $\mathrm{x}$ \\
\hline & & & & & FR717870 & & & & & & \\
\hline & & & & & FR718821 & & & & & & \\
\hline & & Ld46Jag & 000318 & El Jagüey, Sandino & FR717318 & FR716688 & FR750229 & FR734108 & & & \\
\hline & & & & & FR717870 & & & & & & \\
\hline & & & & & FR718821 & & & & & & \\
\hline & & Ld50Gri & 000316 & El Grillo, Sandino & FR717319 & FR716694 & FR750229 & & & & \\
\hline & & & & & FR717870 & & & & & & \\
\hline & & & & & FR718821 & & & & & & \\
\hline & & Ld58Par & 000328 & Paredones, Caimito & FR717320 & FR716699 & FR750229 & FR734113 & FR750387 & FR750343 & \\
\hline & & & & & FR717871 & & & & & & \\
\hline & & & & & FR718821 & & & & & & \\
\hline & & Ld64P & 000354 & Perico Sanchez, Jagüey & FR717321 & FR716710 & FR750229 & & & & \\
\hline & & & & Grande & & & & & & & \\
\hline & & & & & FR717872 & & & & & & \\
\hline & & & & & FR718824 & & & & & & \\
\hline & & Ld73Ch & 000348 & Chicharrones, Bolondrón & FR717323 & FR716717 & FR750229 & & & & \\
\hline & & & & & FR717870 & & & & & & \\
\hline & & & & & FR718826 & & & & & & \\
\hline & & Ld79Ju & 000333 & Juanelo Piedra, Quivicán & FR717320 & FR716699 & FR750229 & & & & \\
\hline & & & & & FR717871 & & & & & & \\
\hline & & & & & FR718821 & & & & & & \\
\hline & & Ld87Car & 000362 & La Carreta, Agramonte & FR717321 & FR716711 & FR750229 & FR734108 & FR750388 & FR750343 & \\
\hline & & & & & FR717873 & & FR750230 & & FR750389 & & \\
\hline & & & & & FR718824 & & & & & & \\
\hline & & Ld91Rat & 000364 & Ratonera, Agramonte & FR717322 & FR716709 & FR750229 & FR775425 & & & \\
\hline & & & & & FR717874 & & & & & & \\
\hline & & & & & FR718825 & & & & & & \\
\hline & Lucifuga sp. 1 & Lnsp1_003E ${ }^{\mathrm{f}}$ & 000389 & El Estadio, Cardenas & FR717324 & FR716722 & FR750229 & & & & \\
\hline & & & & & FR717875 & & FR750232 & & & & \\
\hline & & & & & FR718827 & & & & & & \\
\hline & & Lnsp1_004E & 000390 & El Estadio, Cardenas & FR717325 & FR716723 & FR750229 & FR734122 & & & \\
\hline & & & & & FR717875 & & FR750243 & & & & \\
\hline & & & & & FR718827 & & & & & & \\
\hline & & Lnsp1_005E $E^{f}$ & 000391 & El Estadio, Cardenas & FR717325 & FR716725 & FR750232 & FR734121 & & & \\
\hline & & & & & FR717876 & & FR750243 & & & & \\
\hline & & & & & FR718827 & & & & & & \\
\hline & & Lnsp1_015S $\mathrm{f}^{\mathrm{f}}$ & 000415 & Saturno, Matanzas ${ }^{\mathrm{h}}$ & FR717327 & FR716727 & FR750229 & FR734120 & & & \\
\hline
\end{tabular}




\begin{tabular}{|c|c|c|c|c|c|c|c|c|c|c|c|}
\hline \multirow[t]{2}{*}{ Species } & \multirow{2}{*}{$\begin{array}{l}\text { New taxonomical } \\
\text { partitions }\end{array}$} & \multirow{2}{*}{$\begin{array}{l}\text { Sample } \\
\text { identification }\end{array}$} & \multirow{2}{*}{$\begin{array}{l}\text { Voucher } \\
\text { (MFP18) }^{\mathrm{a}}\end{array}$} & \multirow{2}{*}{$\begin{array}{l}\text { Collection locality } \\
\text { (cave, municipality) }\end{array}$} & \multirow[t]{2}{*}{$\mathrm{mtDNA}^{\mathrm{b}}$} & \multirow[t]{2}{*}{$c y t b^{c}$} & \multicolumn{5}{|c|}{ Nuclear genes } \\
\hline & & & & & & & Rhod & $e v x 1$ & CAM-4 & $S 7-1$ & $\mathrm{Iso}^{\mathrm{d}}$ \\
\hline & & & & & $\begin{array}{l}\text { FR717878 } \\
\text { FR718828 }\end{array}$ & & & & & & \\
\hline & & Lnsp1_025E ${ }^{f}$ & 000392 & El Estadio, Cardenas & FR717325 & FR716724 & FR750229 & FR734124 & & & \\
\hline & & & & & FR717875 & & FR750233 & & & & \\
\hline & & & & & FR718827 & & & & & & \\
\hline & & Lnsp1_026E ${ }^{f}$ & 000412 & El Estadio, Cardenas & FR717325 & FR716723 & & & & & \\
\hline & & & & & FR717877 & & & & & & \\
\hline & & & & & FR718827 & & & & & & \\
\hline & & Lnsp1_028S ${ }^{\mathrm{f}}$ & 000416 & Saturno, Matanzas ${ }^{\mathrm{h}}$ & FR717327 & FR716728 & & FR734123 & & & \\
\hline & & & & & FR717878 & & & & & & \\
\hline & & & & & FR718827 & & & & & & \\
\hline & & Lnsp1_36Ag & 000396 & del Agua, Matanzas & FR717326 & FR716726 & FR750229 & FR734119 & FR750387 & FR750344 & $\mathrm{x}$ \\
\hline & & & & & FR717878 & & & & & & \\
\hline & & & & & FR718829 & & & & & & \\
\hline & & Lnsp1_53E ${ }^{\mathrm{f}}$ & NV & El Estadio, Cardenas & FR717325 & FR716723 & & & & & \\
\hline & & & & & FR717875 & & & & & & \\
\hline & & & & & FR718827 & & & & & & \\
\hline & Lucifuga sp. 2 & Lnsp2_012f & 000397 & $\begin{array}{l}\text { Cave 1, Habana del Este, } \\
\text { Havana City }\end{array}$ & FR717328 & FR716729 & FR750236 & FR734125 & & & \\
\hline & & & & & FR717879 & & FR750237 & & & & \\
\hline & & & & & FR718830 & & & & & & \\
\hline & & Lnsp2_013 ${ }^{f}$ & 000398 & $\begin{array}{l}\text { Cave 1, Habana del Este, } \\
\text { Havana City }\end{array}$ & FR717328 & FR716729 & FR750236 & & & & \\
\hline & & & & & FR717880 & & FR750238 & & & & \\
\hline \multirow{5}{*}{ Lucifuga simile } & & & & & FR717329 & & & & & & \\
\hline & Lucifuga simile & Lsim011GPG & 000408 & $\begin{array}{l}\text { Grieta Punta de Guana, } \\
\text { Matanzas }\end{array}$ & FR717329 & FR716730 & FR750234 & FR734124 & FR750387 & FR/50345 & \\
\hline & & & & & $\begin{array}{l}\text { FR717881 } \\
\text { FR718832 }\end{array}$ & & & & & & \\
\hline & & Lsim014GPG ${ }^{e, f}$ & 000419 & $\begin{array}{l}\text { Grieta Punta de Guana, } \\
\text { Matanzas }\end{array}$ & FR717329 & FR716730 & FR750234 & FR734126 & & & \\
\hline & & & & & $\begin{array}{l}\text { FR717882 } \\
\text { FR718832 }\end{array}$ & & FR750235 & & & & \\
\hline \multirow[t]{19}{*}{ Lucifuga subterranea } & Lucifuga subterranea & Ls10Ban & NV & Baño2, Artemisa & FR717330 & FR716731 & FR750239 & FR734127 & & & $\mathrm{x}$ \\
\hline & & & & & FR717883 & & FR750240 & & & & \\
\hline & & & & & FR718834 & & & & & & \\
\hline & & Ls12Emi & 000378 & Emilio, Artemisa & FR717330 & FR716731 & FR750239 & FR734133 & & FR750346 & $\mathrm{x}$ \\
\hline & & & & & FR717883 & & FR750241 & & & & \\
\hline & & & & & FR718833 & & & & & & \\
\hline & & Ls30Sit & 000383 & El Sitio, Artemisa ${ }^{\mathrm{g}}$ & FR717330 & FR716731 & FR750239 & FR734127 & & & $\mathrm{x}$ \\
\hline & & & & & FR717883 & & & & & & \\
\hline & & & & & FR718834 & & & & & & \\
\hline & & Ls37Lec & 000200 & La Lechuza, Artemisa & FR717330 & FR716732 & FR750239 & FR734129 & FR750390 & FR750346 & \\
\hline & & & & & FR717883 & & & FR734127 & & & \\
\hline & & & & & FR718834 & & & & & & \\
\hline & & Ls59Par & 000199 & Paredones, Caimito & FR717331 & FR716732 & FR750239 & FR734127 & & FR750346 & \\
\hline & & & & & FR717883 & & & & & & \\
\hline & & & & & FR718835 & & & & & & \\
\hline & & Ls83Ju & 000372 & Juanelo Piedra, Quivicán & FR717330 & FR716732 & FR750239 & FR734127 & & & \\
\hline & & & & & FR717883 & & & & & & \\
\hline & & & & & FR718834 & & & & & & \\
\hline & & Ls84Ju & 000373 & Juanelo Piedra, Quivicán & FR717330 & FR716732 & FR750239 & FR775426 & & & \\
\hline
\end{tabular}




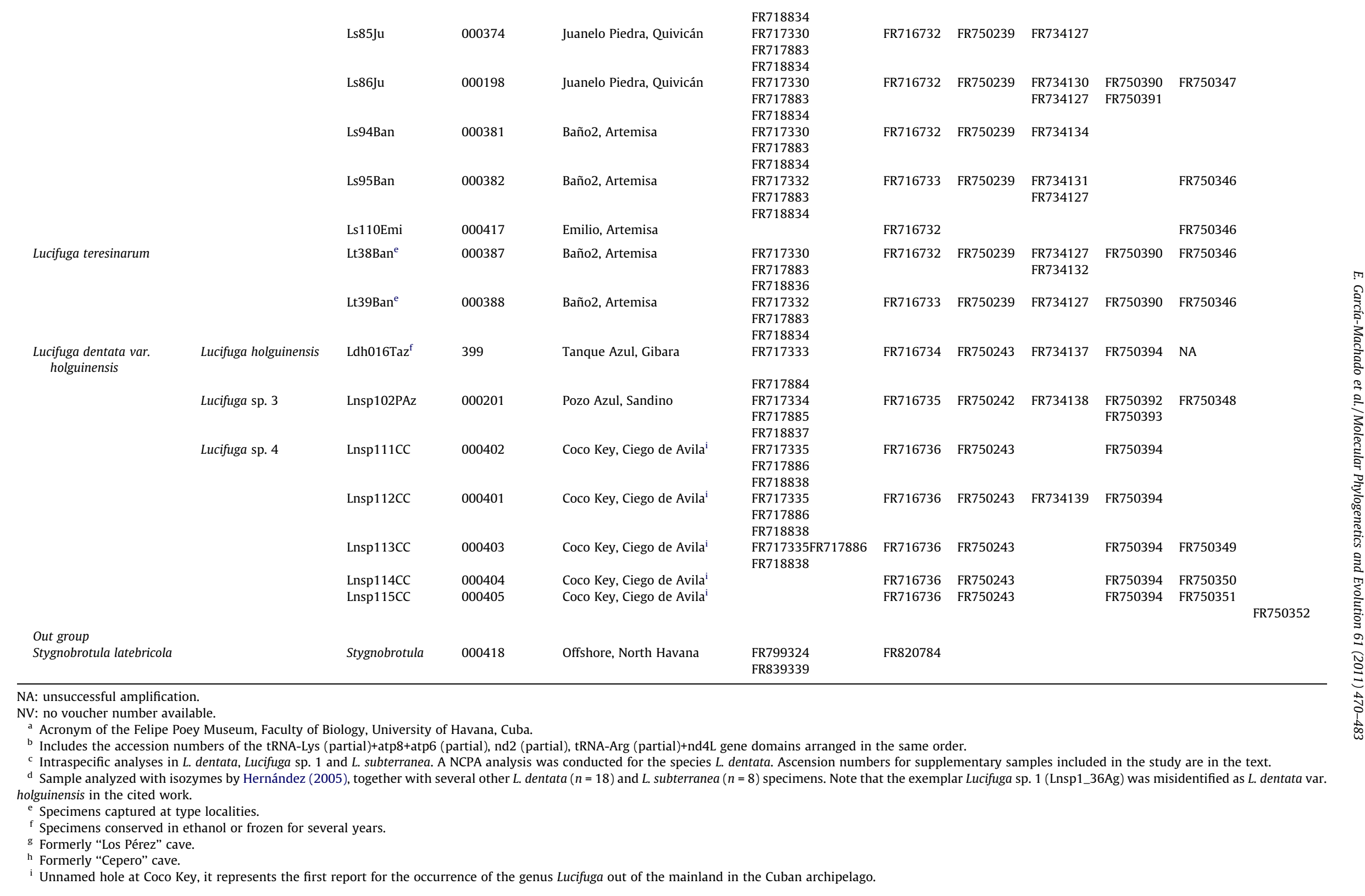


Wiens and Servedio (2000) because small sample sizes hampered handling frequency data.

\subsection{Intraspecific phylogeography}

We used the $c y t b$ sequences ( $810 \mathrm{bp}$ ) to construct haplotype networks in those cases (i.e. L. dentata, Lucifuga sp. 1, and L. subterranea) for which more than one haplotype was identified and where individuals from several localities were available. For the species $L$. dentata and $L$. subterranea the data set was expanded to include more localities as well as additional samples per locality (L. dentata accession numbers: FR716685-FR716687, FR716689, FR716691FR716693, FR716695-FR716706, FR716708-FR716721; L. subterranea accession numbers: FR716731-FR716732).

Parsimony networks were obtained using the statistical parsimony method implemented in TCS v 1.21 (Clement et al., 2000). A nested clade phylogeographic analysis (NCPA) (Templeton et al., 1987; Templeton and Sing, 1993; Templeton, 2009) was carried out to uncover major patterns and processes underlying haplotype distribution in L. dentata. The program GEODIS v 2.6 (Posada et al., 2000) was used with 10,000 random permutations to calculate the significance of associations between genetic distances and geographic distribution of haplotypes. The inference of historical processes explaining the current patterns of haplotype distribution was obtained using the most recent (April 28th, 2009) inference key provided on the GEODIS webpage (http://darwin.uvigo.es/software/geodis.html).

\subsection{Hypothesis testing of phenotypic character evolution}

We examined the phylogenetic distribution of four discrete phenotypic traits (caudal-dorsal-anal fin relationships; degree of pigmentation of the eyes; presence/absence of palatine teeth; and number of caudal fin rays) in all individuals. We checked for character stability by analysing, when possible, additional individuals from the fish collection of the Felipe Poey Museum. In total we examined 94 L. dentata, two L. dentata var. holguinensis, 22 L. simile, 41 L. subterranea, four $L$. teresinarum (including type and paratype), six Lucifuga sp. 1, two Lucifuga sp. 2, and two Lucifuga sp. 3 individuals. For the outgroup, all characters were set as unknown. The program BayesTrait (Pagel and Meade, 2006) was used to estimate character state evolution. To reconstruct ancestral states and obtain their associated likelihood values, a sample of 17,500 trees generated by $\mathrm{MrBa}-$ yes 3.1.2 (Ronquist and Huelsenbeck, 2003) were used. The estimates were obtained using the reversible-jump MCMC and the BayesMultiState methods (Pagel et al., 2004). The likelihood values of the alternative hypotheses were compared using the Bayes factor criteria according to the expression $L R=[\log ($ harmonic mean of the better model $)-\log ($ harmonic mean of the worst model $)] \times 2$. Significant association of a tested character state at a given node was assumed when differences were higher than two, values higher than five were considered "strong" and those higher than 10 "very strong” (Pagel and Meade, 2006).

\section{Results}

\subsection{Phylogenetic inference using mitochondrial sequences}

For the 45 Lucifuga individuals and five outgroups (B. zenkevitchi, C. rubrirostris, D. brachysoma, L. niger and S. latebricola), the concatenated mitochondrial gene sequences totaled 1982 aligned bp [ATP6 (245 bp), ATP8 (158 bp not including the nucleotides overlapping with ATP6), tRNA ${ }^{\text {Arg }}$ (9 bp), tRNA ${ }^{\text {Lys }}$ (23 bp), cytb (810 bp), ND2 (439 bp), ND4L (297 bp)]. For Lucifuga var. holguinensis (Ldvh016TAz) we were unable to amplify $22 \%$ of the aligned sequence (particularly ND2 and ND4L). Similarly, 38.6\% of the data was missing for S. latebricola (about half of the cytb domain and ND2 segment). A total of 547 variable sites, defining 33 haplotypes, were identified among the ingroup sequences (966 variable sites when outgroups were included), 435 were parsimony-informative. There was no difference in length between protein coding sequences, and no stop codons were detected, indicating that the amplified domains were functional. A single indel was observed in the T $\psi C$ arm of tRNA ${ }^{\text {Lys }}$, L. subterranea and L. teresinarum shared a nucleotide deletion at this site.

For the phylogenetic inference, we first analyzed each protein coding sequence independently using $\mathrm{NJ}$ and $\mathrm{ML}$ reconstruction methods. NJ and ML trees were inferred using TrN (Tamura and Nei, 1993) or HKY (Hasegawa et al., 1985) evolutionary models, and the gamma shape or invariant correction parameter estimated for each gene. In all cases, the trees showed essentially the same topology, and invariably the same terminal clades were recovered. A partition homogeneity test analysis (Farris et al., 1995) supported these observations (data not shown). The clade support for some internal nodes was different depending on the gene being analysed and the method being used, possibly due to the relative low number of phylogenetically informative sites at each locus. We therefore concatenated the five protein coding and tRNA gene sequences into a single data set. All subsequent analyses were performed using this dataset.

The evolutionary model estimation indicated that TrN model best fitted the data, with corrections for heterogeneity in site substitution rates $(\Gamma$, shape parameter $\alpha=0.958)$ and invariants $(I=0.348)$

The main incongruence among trees inferred from nucleotide sequence was within the outgroup, in particular the position of $S$. latebricola with respect to the other Bythitidae clades: Lucifuga and Cataetyx + Diplacanthopoma. ML and Bayesian inference placed S. latebricola as a sister group to Cataetyx + Diplacanthopoma, while NJ tree implied a sister relationship with Lucifuga (results not shown). However, support values for alternative topologies were not strong, probably because of the amount of missing data for $S$. latebricola (Philippe et al., 2004; Wiens, 2006).

Eight clades were identified within Lucifuga (Fig. 2). Individuals of the nominal four species (L. dentata, L. simile, L. teresinarum and L. subterranea) that had been previously described based on morphological characters (Poey, 1858; Nalbant, 1981; Díaz, 1988), were found in just three of these clades. A highly supported node (bootstrap $=100 \%$ and Bayesian posterior probability $=1.0$ ) links the two lineages that includes the species $L$. dentata $+L$. simile and $L$. subterranea, respectively. The two individuals from the fourth species, L. teresinarum (Lt39Ban and Lt38Ban) clustered confidently within the subterranea lineage and shared haplotypes with subterranea individuals. They were identified as L. teresinarum on the basis of only one of the two diagnostic characters, the presence of a caudal fin separated from the dorsal and anal fins; L. subterranean has a fused caudal fin (Fig. 2). Five other well supported terminal clades were recovered among the Lucifuga. Two are composed of individuals with $L$. dentata-like morphology ("L. dentata-like"), designated Lucifuga sp. 1 and sp. 2. Three are composed of individuals with $L$. dentata var. holguinensis-like morphology ("holguinensis-like"), L. dentata var. holguinensis, and two clades designated Lucifuga sp. 3 and sp. 4. Higher level relationships indicate that the $L$. dentata + Lucifuga sp. 1 clade together with the $L$. simile + Lucifuga sp. 2 clade represents a monophyletic assemblage, and that the lineage leading to $L$. subterranea $(+L$. teresinarum $)$ diverged before the diversification of the $L$. dentata and allies clade (Fig. 2). Finally, the L. dentata var. holguinensis like clade represents a sister clade to the rest of the Lucifuga lineages.

The first $L$. dentata-like clade, $L$. dentata sensu stricto, included individuals collected at the localities from southern Matanzas to 


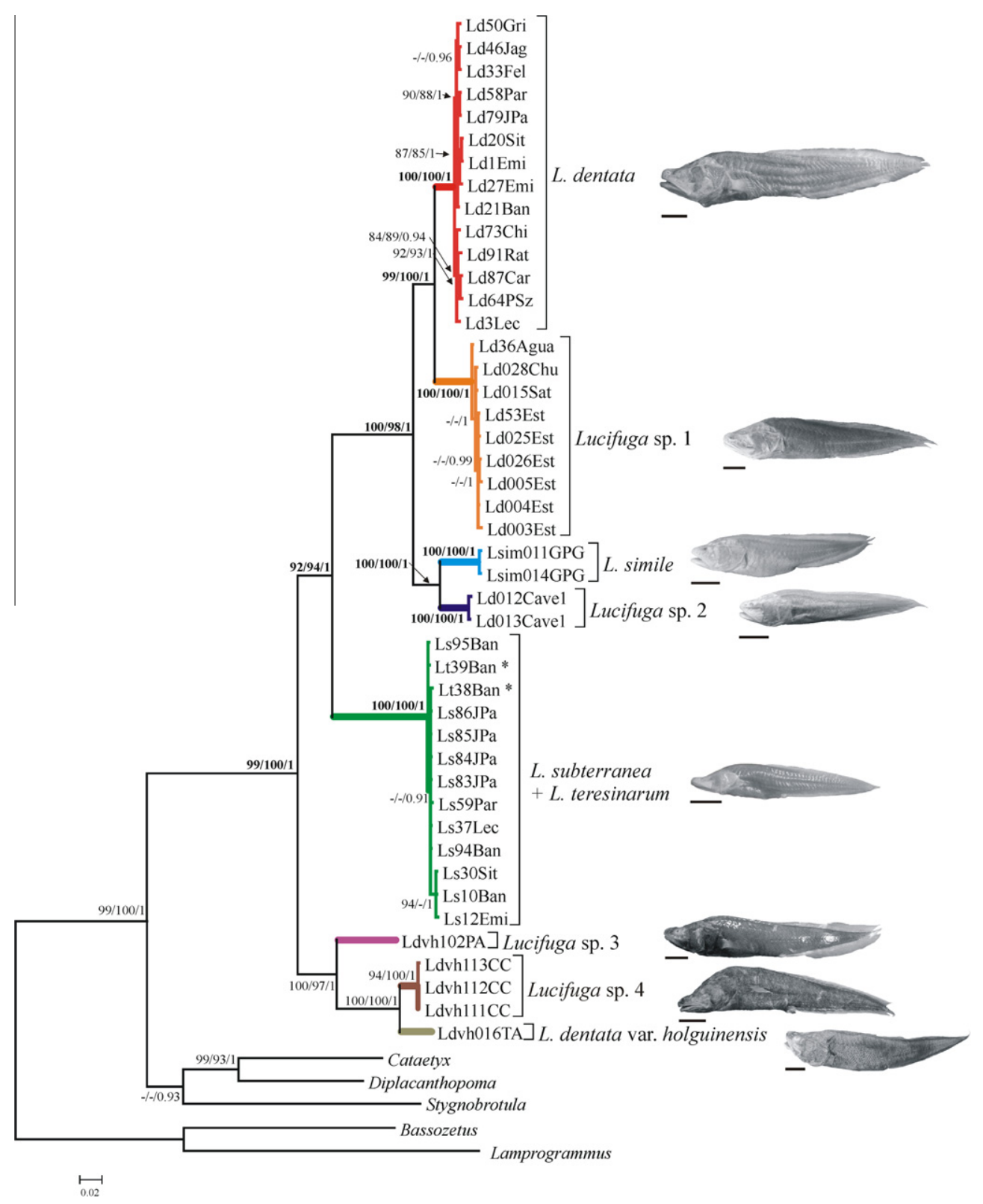

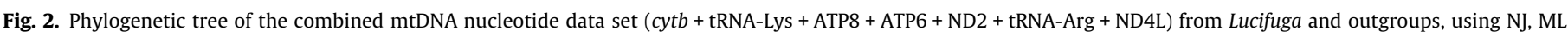

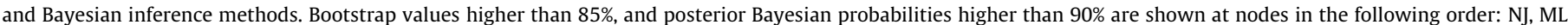
and Bayesian inference. Asterisks indicate the specimens identified as L. teresinarum using morphological characters.

southern Pinar del Río Provinces (see Fig. 1). The second, Lucifuga sp. 1 (see Table 1 ), which fell out as a sister lineage to $L$. dentata, included individuals distributed throughout different localities in the north-eastern Matanzas region (see Fig. 1). The third, Lucifuga sp. 2, which fell out as a sister lineage to L. simile, contained the two individuals found in just one unnamed cave (Cave 1) near the coast of North Havana City. The L. dentata var. holguinensis-like clade includes three lineages. The first is a single individual of $L$. dentata var. holguinensis from Tanque Azul (Gibara, Holguín) a place relatively close to the first locality where it was reported (Díaz et al., 1987b), the second, Lucifuga sp. 4, comprises all individuals (designated as Lucifuga sp. 4) sampled at Coco Key locality, which fell out as a sister lineage of $L$. dentata var. holguinensis. The third is a single specimen, Lucifuga sp. 3, from Pozo Azul (Sandino) at the western part of the island, that fell out as a sister to the other two lineages (Fig. 2, Table 1).

\subsection{Character based analysis of nuclear gene variation}

The amplification of the nuclear sequence markers was particularly problematic for samples preserved for a long time and for the outgroup (i.e. S. latebricola). Nevertheless, we amplified the Rhod and evx 1 regions for 65 and 63 individuals, respectively, but as we show below the sequence variation was quite low. In an effort to collect more information for nuclear genes, other regions were assayed (Ald, CAM-4, CK, Ldh, Rag1, S7-1, Tmo, and TPI). However, reliable amplifications were only obtained for CAM-4, Rag1, and S7-1, though the Rag1 sequences were invariable between species. These gene sequences were obtained for a reduced subset of samples and clades. An overall low variation was observed at these nuclear gene regions. As shown below, the occurrence of most of the fixed alleles in species with a higher sample number and wider geographic distribution (e.g.: L. dentata and L. subterranea) justifies 


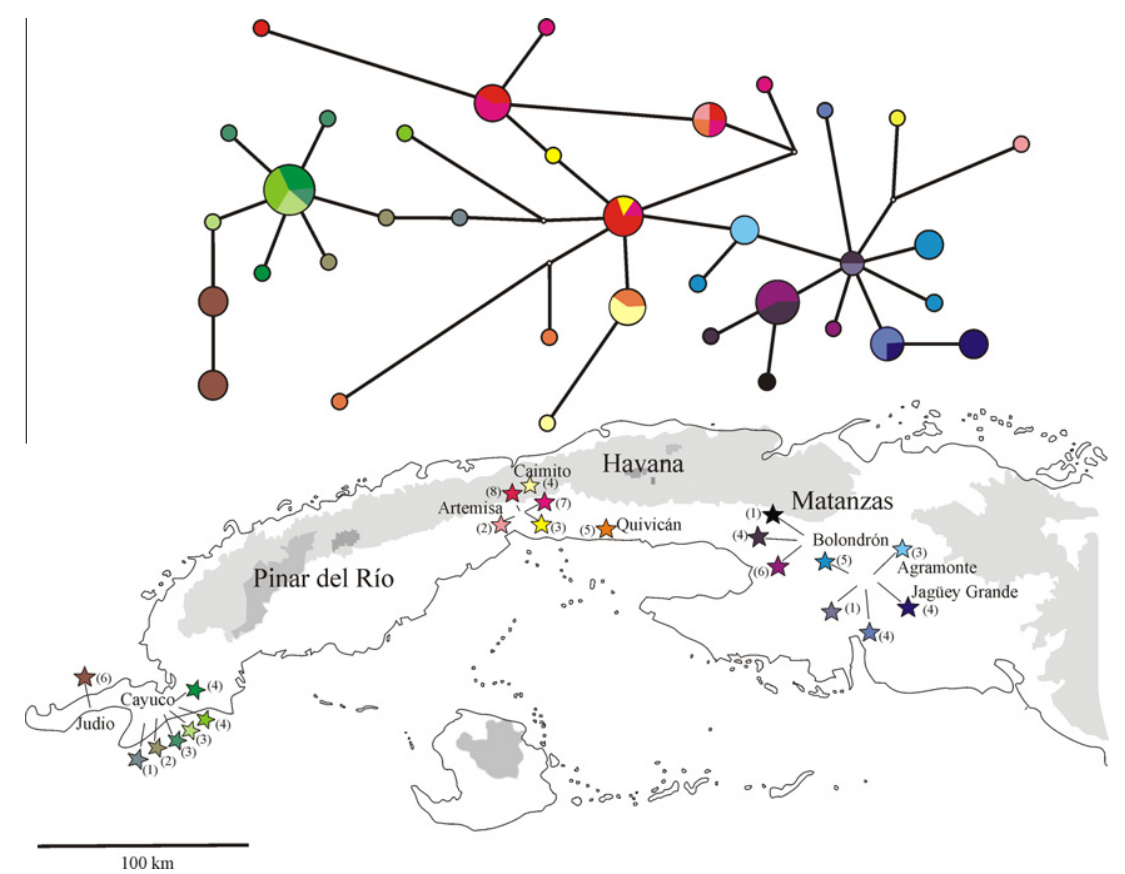

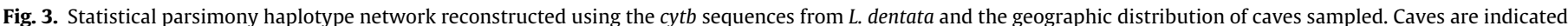

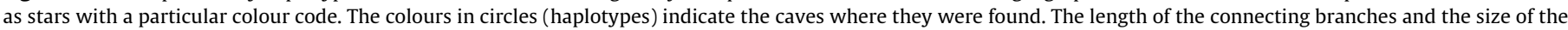

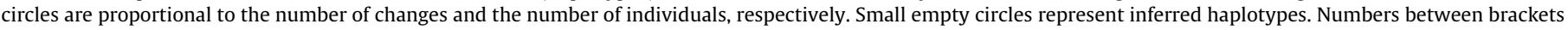
are the sample sizes for each locality. (For interpretation of the references to colour in this figure legend, the reader is referred to the web version of this article.)

the use of PAA in this case. However, as the method is sensitive to sampling errors of individuals and characters (Davis and Nixon, 1992; Sites and Marshall, 2003), the results should be taken with caution because of the limited number of available samples for several taxa.

The Rhod gene region ( $373 \mathrm{pb}$ ) had 10 variable sites, six of them were diagnostic for four of the lineages. Conceptual translation of four of these mutations resulted in amino acid substitutions. The evx 1 intron (565 bp aligned positions) had 15 variable sites, including eight diagnostic sites. The CAM- 4 gene ( $441 \mathrm{bp}$ aligned positions) had nine variable sites, and five of them were diagnostic in distinguishing two lineages from the rest. Finally, there were 28 polymorphisms in the $57-1$ intron sequence, ( 747 bp aligned positions), and 19 of these diagnostically defined three lineages (Fig. 4).

As observed for the mtDNA, all of the nuclear gene sequences for L. teresinarum were identical to that of L. subterranea (Fig. 4). This lineage could be distinguished from the others by 12 unique site variations across the four genes, including two amino acid replacement substitutions in the Rhod gene (positions 45 and $66)$. The mtDNA lineages L. simile and Lucifuga sp. 2 had only one diagnostic site each, in the Rhod gene. In Lucifuga sp. 2 the observed nucleotide substitution codes for an amino acid replacement. Unfortunately, for these individuals we could not amplify the CAM-4 and S7-1 regions. L. dentata var. holguinensis was distinguished by only two nucleotide sites in the evx 1 intron, information was unavailable for the S7-1 region. The Lucifuga sp. 3 lineage had the highest number of diagnostic nucleotide sites (13), and one of them was a gap accounting for a several nucleotide repetition in the evx 1 intron. Lucifuga sp. 4 had six diagnostic nucleotide sites, all in the S7-1 intron. Unfortunately, no information was available for $L$. dentata var. holguinensis, its closest relative as inferred by the mtDNA phylogeny. Finally, L. dentata and Lucifuga sp. 1 could not be distinguished when all the lineages were analyzed jointly. However, these lineages can be distinguished from each other by two nucleotide sites (positions 36 and 37) in the S7-1 intron.
The three major clades identified by the mtDNA data can be distinguished by various diagnostic nuclear nucleotide site positions. We were unable to be definite about whether the variants were diagnostic or not because data is missing for some lineages. Still, the dentata-like clade had seven possible diagnostic nucleotide variants (CAM-4, positions 185 and 235; S7-1, positions 346 and 350; evx1, positions 158, 241 and 275), L. subterranea (+L. teresinarum) clade had at least 13 unique nucleotide variants scattered among all four genes, and in the holguinensis-like clade there were probably two in the $57-1$ (position 373) and evx1 (position 146) introns (Fig. 4).

\subsection{Intraspecific mtDNA phylogeography}

For the three clades with a large enough sample size, i.e. L. dentata, Lucifuga sp. 1 and L. subterranea + L. teresinarum, haplotype diversity was examined.

At present, $L$. dentata sensu stricto is the only one species with a wide geographic distribution, whereas all the other studied clades/ populations are more or less restricted to particular geographic regions or isolated locations. Although for Lucifuga sp. 1 it was not possible to test for associations among haplotypes and their geographic distribution, the distribution of haplotypes per locality indicated that haplotypes are probably not shared between caves (Supplementary material 2). Haplotype and nucleotide diversity were relatively high $(H d=0.96 \pm 0.008 ; \pi=0.0049 \pm 0.00024)$, with only one haplotype shared by three individuals out of the nine analyzed. A different pattern was observed in the $L$. subterranea $+L$. teresinarum lineage, where only three haplotypes were detected in a total of 23 individuals from six caves (Supplementary material 2). A single haplotype was shared by all sampled localities, whereas two others were restricted to the region of Artemisa (Baño II, Emilio, La Lechuza, and El Sitio caves). In contrast, there was relative higher haplotypic divergence $(k=3.99 \pm 0.319$ vs. $k=1.55 \pm 0.468$ within Lucifuga sp. 1) in this lineage, which suggests that there has been a longer period of evolutionary 


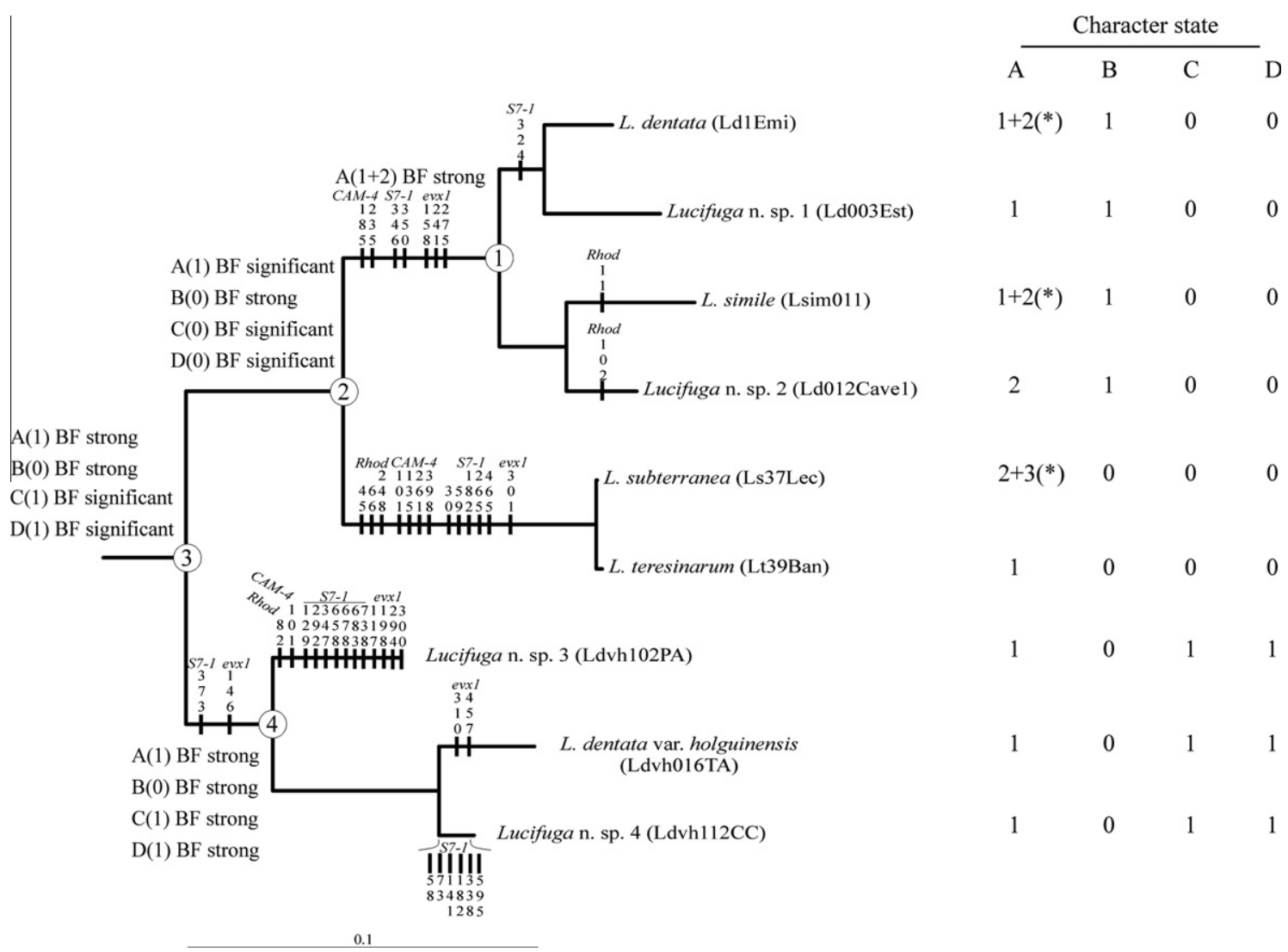

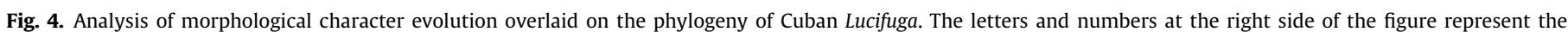

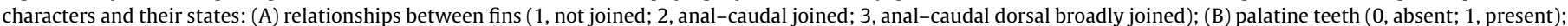

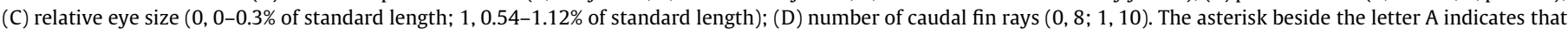
the frequency of the anal-caudal joined condition is low with respect to the alternative condition.

divergence within L. subterranea and probably secondary contact of the two divergent mtDNA lineages in Artemisa. Moreover, it should be noted that $L$. teresinarum had haplotypes LsH1 and LsH3 (Supplementary material 2).

The haplotype network inferred and the nested design for $L$. dentata are shown in Fig. 3 and Supplementary material 2. A total of 36 haplotypes were identified from a total of 80 individuals analyzed. The NCPA showed that significant associations between haplotype clades and their geographical locations were obtained at the highest nesting levels (i.e. 2-step and 3-step clades). For the total cladogram, long-distance colonization [Havana caves (nested level 3-2) to Pinar del Río caves (nested level 3-1)] and past fragmentation [Havana caves vs. Matanzas caves (nested level 3-3)] processes appear to best explain the present haplotype pattern throughout the species range. However, these and other processes were also suggested within very restricted geographic ranges and

Table 2

Evolutionary interpretations of the NCPA L. dentata cytb nested contingency results and inferred patterns.

\begin{tabular}{lrlll}
\hline Clade & \multicolumn{1}{c}{$\chi^{2}$} & Probability & Inference chain & Inferred pattern \\
\hline $2-1$ & 37.71 & 0.000 & $1-2-3-5-15-N o$ & LDC \\
$2-7$ & 64.80 & 0.000 & $1-2-3-5-15-N o$ & LDC \\
$3-3$ & 29.00 & 0.008 & $1-19-N o$ & AF \\
Total & 147.31 & 0.000 & $1-2-11-12-13-14-N o$ & LDC and PF
\end{tabular}

$\chi^{2}$ signification based on 10,000 permutations. Inferences were made using the most recent (April 28th, 2009) inference key provided on the GEODIS webpage (http://darwin.uvigo.es/software/geodis.html). AF: allopatric fragmentation; LDC, long distance colonization; PF, past fragmentation. time periods (Table 2, Supplementary material 2). Namely, the analysis suggests that a recent dispersal event occurred since two highly derived haplotypes, from Matanzas ancestors, were found in two caves (La Lechuza and El Sitio) in the Aston cave system (Artemisa, Havana) (see Fig. 1; Table 1). This event was also inferred with confidence (data not shown) using the coalescent based analysis implemented in the MIGRATE software (Beerli, 1997-2008). Finally, we calculated the number of steps connecting Lucifuga sp. 1 cytb haplotypes to the L. dentata cytb network. A minimum of 31 steps were required, which is outside the $95 \%$ confidence level used to infer haplotype connections (data not shown).

\subsection{Morphological character variation in the light of the phylogeny}

Some of the lineages studied had morphological characters previously considered to be restricted to Bahamian species, we therefore re-analyzed four morphological characters that have been previously used in Lucifuga taxonomy. In particular, the occurrence of relatively large pigmented eyes and ten caudal fin rays have been used to distinguish the Bahaman species from those in Cuba. $L$. dentata, $L$. simile, $L$. subterranea $+L$. teresinarum, and the newly described lineages (Lucifuga sp. 1 and Lucifuga sp. 2) all have a dramatic loss of eye pigmentation [0-0.3\% of the standard length (SL)] and eight caudal fin rays. However, the hoguinensis-like lineages, $L$. dentata var. holguinensis, Lucifuga sp. 3 and 4 showed the same character states observed in Bahamian species: the diameter of the eye pigment ranged from between $0.54 \%$ and $1.12 \%$ SL, and all have ten caudal fin rays.

The presence/absence of palatine teeth showed a slightly different pattern, all the $L$. dentata-like clades, $L$. dentata, $L$. simile, Lucifuga 
sp. 1 and 2, have palatine teeth, while those within the L. subterranea $+L$. teresinarum and the three holguinensis-like clades lack palatine teeth. On the other hand, the caudal-dorsal-anal fin relationships were much more variable. We found that two individuals of the species L. dentata (from Perico Sánchez and Chicharrones caves), the two Lucifuga sp. 2, and the four L. subterranea (from Juanelo Piedra cave) individuals had joined caudal-anal fins and separated dorsal fins. Several individuals of L. dentata, one Lucifuga sp. 3, and some Lucifuga sp. 4 individuals had membranes connecting the three fins basally (included with the individuals with completely separated fins in Fig. 4). These conditions were previously thought to be confined to L. simile (Díaz et al., 1987b). Finally, holguinensis-like individuals had the caudal fin separated from the dorsal and anal fins.

The result of the analysis using the BayesMultiState option (Pagel et al., 2004) in BayesTrait (Pagel and Meade, 2006) is shown in Fig. 4 and Supplementary material 3. Significant associations between the distribution of character states and the phylogenetic hypothesis were found for all four characters. The analysis of caudal-dorsal-anal fin relationships strongly suggested that for Cuban species the most probable ancestral condition was a separated caudal fin. This state remains the most probable for all the most basal nodes (Fig. 4). Finally, the degree of pigmentation of the eyes and the number of caudal fin rays showed the same phylogenetic distribution. According to the phylogenetic analysis, highly pigmented eyes and ten rays in the caudal fin, as observed in the holguinensis-like clade, appear to be the ancestral condition. A reduction on the number of caudal fin rays (eight rays) and a complete or partial loss of eye pigmentation most likely evolved in the common ancestor of $L$. dentata and allies and $L$. subterranea $+L$. teresinarum clade.

\section{Discussion}

The current study provides the first phylogenetic analysis of the Cuban species of the genus Lucifuga using molecular data, and shows that a reappraisal of the taxonomic status and geographic distribution of the evolutionary units of this genus should be undertaken, including the recognition of candidate morphologically cryptic species. Evolutionary lineage distribution and phylogeographic inferences also showed that both dispersal and vicariant processes have occurred in the evolution of this cave-fish genus.

\subsection{Phylogeny and phylogeographical patterns}

The genus Lucifuga is an assemblage with three main clades in Cuba: (i) L. dentata and allies; (ii) $L$. subterranea $+L$. teresinarum and (iii) holguinensis-like lineage. The first two clades correspond to previously described morphological partitions (Poey, 1858; Vergara, 1980; Nalbant, 1981) but the third one represents a new lineage, which, however, has been previously indicated by COI sequence variation analysis of Cuban freshwater fishes (Lara et al., 2010).

The character based analysis of the nuclear genes supported the main partitions described above, although the number of diagnostic sites per clade was variable. The $L$. subterranea $+L$. teresinarum clade had the highest number of diagnostic sites (13), followed by the $L$. dentata-like clade (7) and the holguinensis-like clade (2). However, this result may be highly influenced by the available sample size and the lack of information for some lineages so the results presented here should be taken with caution. Nevertheless, the low sequence variation observed in nuclear genes (i.e. evx 1 and Rhod) for which the number of individuals analyzed was relatively larger (i.e. $L$. dentata and $L$. subterranea) suggests that the general trend is probably similar for other genes. In addition, pre- vious analysis of 28 isozymes and general protein loci revealed complete monomorphy in $24 \mathrm{~L}$. dentata, $11 \mathrm{~L}$. subterranea and one Lucifuga sp. 1 (Lnsp1_36Ag) individuals (see also Table 1). However, 11 loci (Est3, 6 and 7; Mdh2; Per1 and 2; GP 4, 5, 7, 8, 9 and 10; SOD) showed clear differentiation of L. dentata and Lucifuga sp. 1 from L. subterranea (Hernández, 2005).

Although well supported, the deepest branches connecting the three major clades are relatively short, strongly suggesting that the most of the internal speciation events happened quite rapidly. This pattern is also apparent when observing the branches connecting sister terminal lineages which show that the splits probably took place relatively simultaneously followed by a rapid sorting of the mtDNA haplotypes. We hypothesize that most of them have occurred during the last few million years when paleogeographic events shaped the present archipelago, and that the most recent splits probably have occurred during a more recent common paleogeographic event. The strong geographical structure within lineages (i.e. L. dentata) and among different lineages (species) suggests that the underground aquifers have not been connected for a very long time, if ever. The distribution of most of the populations is peripheral, closely related to coastal margins (see Fig. 1), evidenced by the wide tolerance to salinity in these species. Habitat availability is particularly important in the evolution of this group of stygobiotic fishes whose marine ancestor dwelled in shallow waters of the paleoarchipelago. Thus, Vergara (1981) suggested that Lucifuga evolution may have occurred during the late Pliocene-Pleistocene period, when cave and hydrographic systems formed in karstic areas, and recurrent sea level fluctuations may have created conditions suitable for dispersal of these organisms. Indeed, it has been suggested that sea regressions probably represent one of the most significant vicariant events for stygobiotic faunas (Culver et al., 2009). Nonetheless, the relatively recent origin of Lucifuga appears challenged by a high level of mtDNA sequence divergence estimated (around 30\%) at the deepest nodes of the phylogeny. If Vergara's (1981) hypotheses are correct, it means that this genus experienced an accelerated rate of mtDNA sequence evolution. Conversely, initial diversification of Lucifuga may be much older than previously thought.

Intraspecific analyses may shed light on the processes that have moulded the evolution of Lucifuga. For the species with a widest distribution ( $L$. dentata sensu stricto), mechanisms such as longrange dispersal and range fragmentation were inferred and appear to have produced a pattern of population differentiation highly congruent with spatial distribution. In fact, haplotype distribution shows that in several cases caves have unique mtDNA haplotypes, suggesting very restricted or no gene flow between relatively close geographic localities (Slatkin and Maddison, 1989; Martin and Bermingham, 2000). This was also apparent for Lucifuga sp. 1 that has no shared haplotypes among the different caves (Supplementary material 2). This characteristic has been observed for many subterranean species including cave salamanders (Wiens et al., 2003), phalangodid harvestmen (Hedin and Thomas, 2010), amphipods (Lefébure et al., 2006, 2007; Finston et al., 2007), isopods (Verovnik et al., 2005), crayfishes (Buhay and Crandall, 2005), and shrimps (Zakšek et al., 2009). In general, as seen in other stygobiotic fishes [e.g. Schistura oedipus (Borowsky and Mertz, 2001), A. mexicanus (Strecker et al., 2004), Sinocyclocheilus sp. (Xiao et al., 2005)], these findings suggest that under certain circumstances ecologically specialized species can disperse and found new discrete populations, possibly by a very small number of individuals, followed by a rapid drift-induced divergence (Templeton, 1980; Avise, 2000; Bickford et al., 2007). Alternatively, range fragmentation, that is, isolation of cave systems, may have resulted in isolation of populations and genetic differentiation. When extrapolated to the species level, the present distribution of the recognized lineages suggests that dispersal at different geographic scales (e.g. L. dentata var. 
holguinensis and allies lineages), followed by isolation of available habitats and range fragmentation in other instances (e.g. L. dentata and allies lineages) has occurred relatively frequently. In fact, most of the observed terminal lineages have narrow allopatric distributions, closely related to particular karstic patches that have separate geographical histories or are intersected by the orogenesis of mountain ranges that fragmented subterranean aquifers (e.g. the north and south karstic regions of Havana-Matanzas) (see Fig. 1 and also Fig. 115 in Nuñez-Jiménez et al., 1984; Nuevo Atlas Nacional de Cuba, 1989). This phylogeographic pattern has also been observed in other stygobiotic taxa (Buhay and Crandall, 2005; Finston et al., 2007; Lefébure et al., 2007; Zakšek et al., 2007; Page et al., 2008). Although determining the geographic patterns of the speciation process is a difficult task because species ranges certainly change overtime (Losos and Glor, 2003), the evidence from Lucifuga suggests that dispersal and allopatric divergence has driven diversification in this genus.

Two species, L. subterranea and Lucifuga sp. 3 have sympatric distributions with $L$. dentata. The first, $L$. subterranea, has a distribution that completely overlaps with $L$. dentata distribution in the south Havana province while Lucifuga sp. 3 is known from a single locality Pozo Azul, Sandino municipality (western Pinar del Río). As none of these three clades have a sister relationship, sympatric speciation seems unlikely to explain present distributions (Avise, 2000). Mechanisms such as range shifts may better explain the occurrence of these divergent evolutionary lineages in sympatry (Avise, 2000; Knowles, 2001). According to the processes inferred from the phylogeographic analysis, it seems likely that $L$. dentata invaded regions previously occupied by other species (i.e. L. subterranea) (see Table 2). However, this is less clear in the case of $L$. dentata - Lucifuga sp. 3 since the sister clade of the Lucifuga sp. 3 taxon is geographically distant $(>900 \mathrm{~km}$ ) (see Fig. 1). Moreover, similar morphotypes to $L$. dentata var. holguinensis clade have been found from Zapata swamp karstic system, a much closer locality at the south central region of the island, which suggests that the cooccurrence of L. dentata - Lucifuga sp. 3 could be due to colonization (see Fig. 1).

\subsection{Cryptic diversity and taxonomic revisions}

During the last few years candidate cryptic species have been regularly uncovered for several groups of organisms (Bickford et al., 2007) and cave-adapted species appear to be particularly prone to being genetically divergent but morphologically indistinguishable (Lefébure et al., 2006, 2007; Culver and Pipan, 2009; Hedin and Thomas, 2010). Because in an extreme environment (i.e. subterranean environments), organisms are believed to be very constrained in the ways they can adapt, they can be expected to converge in physical characteristics, leading to morphological stasis (Bickford et al., 2007). However, sibling species may evolve, for example via differentiation of mating signals (Bickford et al., 2007). This could be the case for Lucifuga, which, in addition to the nominal species ( $L$. dentata, $L$. simile and $L$. subterranea), includes five other evolutionary clades. Two of the clades, Lucifuga sp. 1 and sp. 2, previously recognized as L. dentata (Poey, 2000; García-Debrás and Pérez, 1999) (though Lucifuga sp. 2 is actually a sibling lineage to $L$. simile) lack diagnostic morphological characters with respect to its nominal sister species. Similarly, there are few morphological differences within the holguinensis-like clade. Mitochondrial DNA sequence divergence was relatively high between sister terminal clades: $4.7-5.7 \%$ (3.5-4.2\% for the cytb); while intraclade divergences (i.e. L. dentata, Lucifuga sp. 1 and L. subterranea for which a larger number of individuals were sequenced) were very low $(0-0.4 \%)$. However, there were few diagnostic nucleotide changes in the nuclear genes in most cases. The most clearly supported clade was Lucifuga sp. 3 that has the largest genetic distance estimates [13.4\% (9.5\% for cytb) and $15.7 \%$ (9.6\% for cytb)] and several distinctive nucleotide site changes with respect to the other two clades (Lucifuga sp. 4 and L. dentata var. holguinensis, respectively) at least for three of the genes (i.e. CAM-4, evx1 and Rhod).

Confirming whether the newly identified clades (i.e. Lucifuga sp. 1, Lucifuga sp. 2, L. dentata var. holguinensis and Lucifuga sp. 4) represent species is challenging because of the lack of diagnostic differences in nuclear genes and the uncertainty of species delimitation based on only one type of genetic marker (Avise and Ball, 1990; Moritz et al., 1992; Sites and Crandall, 1997; Avise, 2000; Baker et al., 2001; Hudson and Turelli, 2003; Ballard and Whitlock, 2004; DeSalle, 2006). However, the significant population structure and range shift events detected in $L$. dentata suggests that sufficient time has elapsed since the split of this species and Lucifuga sp. 1 from a common ancestor. A hierarchical likelihood ratio test (data not shown) did not reject the molecular clock hypothesis, so assuming equal evolutionary rate variation between terminal sister lineages, equivalent evolutionary distances to those observed between $L$. dentata and Lucifuga sp. 1 can serve as yardstick to identify real independent evolutionary lineages in this genus.

The species status of $L$. teresinarum was not supported by mtDNA and nuclear genes. It is now apparent that the two morphological characters used to identify L. teresinarum (i.e. the relationship between the anal-caudal-dorsal fin and the shape of the male genitalia) are highly variable both within and among species (see Fig. 4). We examined all available males in the different lineages described here and found large variation in hood shapes within each lineage. Lucifuga simile, as described by Díaz et al. (1987a), is the only species that has a conical hood shape in all examined male individuals $(n=14)$.

An alternative explanation for the combination of morphological characters observed in $L$. teresinarum is suggested from the sympatric distribution of $L$. dentata and $L$. subterranea in the south Havana region. This suggests that $L$. teresinarum may be a hybrid, a hypothesis which could be tested once diagnostic alleles are available for each parental species (Gow et al., 2006). Although a directional introgression event ( $L$. subterranea females and $L$. dentata males), as suggested by the mtDNA results, cannot be ruled out, neither of the two teresinarum individuals nor the two L. subterranea individuals with a free dorsal fin (Ls84Ju and Ls85Ju from Juanelo Piedra cave) had nuclear alleles diagnostic for $L$. dentata. So, if directional introgression has occurred, this is not apparent from any of the genes sequenced or the evidence has been erased after successive backcrosses with subterranean types.

\subsection{Morphological character evolution}

Several morphological attributes were highly correlated with the three main mtDNA clades. As described previously for $L$. dentata and L. simile (Nalbant, 1981; Díaz et al., 1987a) and now also for Lucifuga sp. 1 and sp. 2, these clades have palatine teeth, very similar head shapes, but have variable anal-caudal-dorsal relationships (see Fig. 4). The species $L$. subterranea sensu lato is morphologically dissimilar to other Lucifuga in that it has a slender body shape, a high frequency of fused anal-caudal-dorsal fins, as well as differences in other morphometric characters (Vergara, 1980). In contrast to the $L$. dentata clade, it lacks palatine teeth (Poey, 1858), a condition shared with holguinensis-like clade and one Bahamian species (L. lucayana). Finally, the holguinensis-like clade has highly pigmented eyes and ten caudal fin rays, in contrast to $L$. dentata and allies $+L$. subterranea, which all have eight caudal finrays and reduced pigment-deficient eyes. A preliminary analysis of the evolution of these morphological characters based on the inferred mtDNA based phylogeny suggests, with moderate statistical support, that the overall character conditions observed in the $L$. 
dentata var. holguinensis clade was present in the common ancestor of Cuban Lucifuga. The analysis also suggests that the acquisition of palatine teeth was a novelty in the L. dentata and allies clade and provides further evidence that generic or subgeneric subdivision of the genus (e.g.: Stygicola and Lucifuga) is unwarranted (Vergara, 1980; Møller et al., 2006). However, phylogenetic relationships between the Cuban and Bahamian species need to be established in order to determine how these discrete morphological features have evolved in Lucifuga.

The two Bahamian Lucifuga species have been distinguished from Cuban species by several morphological character states (Cohen and Robins, 1970; Vergara, 1980; Møller et al., 2006), however they are also present in $L$. dentata var. holguinensis. These findings raise the question of whether the shared morphological similarities between the holguinensis-like clade and Bahamian species indicate common ancestry, retention of plesiomorphic character conditions, or merely represent homoplasies.

\section{General conclusions}

An important conclusion from this study is that the current estimates of species diversity for Lucifuga may be underestimated. This was also seen in a broader molecular barcoding survey of freshwater fishes of Cuba (Lara et al., 2010). If we take into account the number of new evolutionary lineages/candidate species identified and the two Bahamian species, the genus becomes probably one of the most species rich cavefish genus described so far (Romero, 2001; Xiao et al., 2005). We also hypothesized that, given the fragmented nature of the distribution of Lucifuga, further hidden variation may still be waiting to be discovered.

Recent efforts for protecting vertebrate species in Cuba include the creation of a National Red List of species. This list only includes described species, so the results obtained here make a significant contribution towards the recognition of new evolutionary significant units, as well as supplying information about their distribution. Particularly, the extremely restricted geographic distribution for some of them and the introduction of alien species in subterranean ecosystems implies that conservation plans need to be rapidly implemented to preserve the evolutionary legacy of this peculiar group of cave fishes.

\section{Acknowledgments}

We want to thank Michel Solignac for support at very early stages of this study and Manuel Iturralde Vinent and Aymée Robainas Barcia for useful discussion. We are very grateful to Eduardo Abreu, Majorie Condis, Yosvani Hernández, for field assistance and José Luis Ponce de León, Niurka Hernández, Carlos Arredondo and members of the Xaxabi speleological group Dimitri Gómez, Yaniel Pérez, Felix Jonathan Pereira Miller, and Leandro Pérez González who supplied valuable specimens. We would also like to thank Isabelle Germon and Dominique Vautrin for laboratory assistance. We thank the University of Paris 11, the Embassy of France in Cuba and the University of Havana for financial and logistic support during this investigation.

\section{Appendix A. Supplementary material}

Supplementary data associated with this article can be found, in the online version, at doi:10.1016/j.ympev.2011.06.015.

\section{References}

Avise, J.C., 2000. Phylogeography. The History and Formation of Species. Harvard Univ. Press, Cambridge, Massachusetts.
Avise, J.C., Ball, R.M., 1990. Principles of genealogical concordance in species concepts and biological taxonomy. Oxford Surv. Evol. Biol. 7, 45-67.

Avise, J.C., Selander, R.K., 1972. Evolutionary genetics of cave-dwelling fishes of the genus Astyanax. Evolution 26, 1-19.

Baker, R.H., Wilkinson, G.S., DeSalle, R., 2001. Phylogenetic utility of different types of molecular data used to infer evolutionary relationships among stalk-eye flies (Diopsidae). Syst. Biol. 50, 87-105.

Ballard, J.W.O., Whitlock, M.C., 2004. The incomplete natural history of mitochondria. Mol. Ecol. 13, 729-744.

Beerli, P., 1997-2008. MIGRATE Documentation, Version 3.0.3 Revised May 6, 2009, Distributed over the Internet, Seattle, WA. <http://evolution.genetics washington.edu/lamarc/migrate.html>

Bickford, D., Lohman, D.J., Sodhi, N.S., Ng, P.K.L., Meier, R., Winker, K., Ingram, K.K., Das, I., 2007. Cryptic species as a window on diversity and conservation. Trends Ecol. Evol. 22 (3), 148-155.

Borowsky, R.B., Mertz, L., 2001. Genetic differentiation among populations of the cave fish Schistura oedipus (Cypriniformes: Balitoridae). Environ. Biol. Fishes 62, 225-231.

Borowsky, R.L., Vidthayanon, C., 2001. Nucleotide diversity in populations of balitorid cave fishes from Thailand. Mol. Ecol. 10, 2799-2805.

Bradford, T., Adams, M., Humphreys, W.F., Austin, A.D., Cooper, S.J.B., 2009 DNA barcoding of stygofauna uncovers cryptic amphipod diversity in a calcrete aquifer in Western Australia's arid zone. Mol. Ecol. Resour. 10 (1) 41-50.

Buhay, J.E., Crandall, K.A., 2005. Subterranean phylogeography of freshwater crayfishes shows extensive gene flow and surprisingly large population sizes. Mol. Ecol. 14, 4259-4273.

Clement, M., Posada, D., Crandall, K.A., 2000. TCS: a computer program to estimate gene genealogies. Mol. Ecol. 9, 1657-1659.

Cohen, D.M., McCosker, J.E., 1998. A new species of Bythitid fish, genus Lucifuga from the Galapagos Island. Bull. Mar. Sci. 63, 179-187.

Cohen, D.M., Robins, C.R., 1970. A new Ophidioid fish (Genus Lucifuga) from a limestone sink, New Providence Island, Bahamas. Proc. Biol. Soc. Washington 13, 133-144.

Colli, L., Paglianti, A., Berti, R., Gandolfi, G., Tagliavini, J., 2009. Molecular phylogeny of the blind cavefish Phreatichthys andruzzii and Garra barreimiae within the family Cyprinidae. Environ. Biol. Fishes 84 (1), 95-107.

Culver, D.C., Pipan, T., 2009. The Biology of the Caves and other Subterranean Habitats. Oxford University Press.

Culver, D.C., Pipan, T., Schneider, K., 2009. Vicariance, dispersal and scale in the aquatic subterranean fauna of karst regions. Freshwater Biol. 54, 918-929.

Davis, J.I., Nixon, K.C., 1992. Populations, genetic variation, and the delimitation of phylogenetic species. Syst. Biol. 41 (4), 421-435.

DeSalle, R., 2006. Species discovery versus species identification in DNA barcoding efforts: response to Rubinoff. Conserv. Biol. 20, 1545-1547.

DeSalle, R., Egan, M.G., Siddall, H., 2005. The unholy trinity: taxonomy, species delimitation and DNA barcoding. Philos. Trans. Roy. Soc. B 360 (1462), 19051916.

Díaz, P., 1988. Lucifuga teresinarum sp.n., nueva especie cubana de peces troglobios (Ophidiiformes, Bythitidae). Rev. Biol. 2 (2), 37-43.

Díaz, P., Montoto, A., García-Machado, E., 1987a. Morfología externa de ejemplares machos de Lucifuga simile Nalbant, 1981 (Ophidiiformes, Bythitidae). Rev. Biol. 1 (2), 77-84.

Díaz, P., Nieto, E., Abio, G., 1987b. Peces ciegos del género Lucifuga (Ophidiiformes, Bythitidae) en dos casimbas cubanas. Rev. Invest. Mar 8 (1), 41-47.

Dowling, T.E., Martasian, D.P., Jeffery, W.R., 2002. Evidence for multiple genetic forms with similar eyeless phenotypes in the blind cavefish, Astyanax mexicanus. Mol. Biol. Evol. 19, 446-455.

Espinasa, L., Borowsky, R., 2000. Eyed cave fish in a karst window. J. Cave Karst Stud. $62,180-183$.

Espinasa, L., Borowsky, R., 2001. Origins and relationship of cave populations of the blind Mexican tetra, Astyanax fasciatus, in the Sierra de El Abra. Environ. Biol. Fishes 62, 233-237.

Farris, J.S., Kallersjo, M., Kluge, A.G., Bult, C., 1995. Constructing a significance test for incongruence. Syst. Biol. 44, 570-572.

Finston, T.L., Johnson, M.S., Humphreys, W.F., Eberhard, S.M., Halse, S.A., 2007 Cryptic speciation in two widespread subterranean amphipod genera reflects historical drainage patterns in an ancient landscape. Mol. Ecol. $16,355-365$.

García-Debrás, A., Pérez, A., 1999. Estudio sobre la dieta de peces ciegos cubanos (Ophidiiformes: Bythitidae). Troglobio 4, 2-3.

García-Debrás, A., Pérez, A., Yager, J., 1999. Distribución geográfica de los peces ciegos (Ophidiiformes, Bythitidae) cubanos. Troglobio 5, 2-4.

Gow, J.L., Peichel, C.L., Taylor, E.B., 2006. Contrasting hybridization rates between sympatric three-spined sticklebacks highlight the fragility of reproductive barriers between evolutionarily young species. Mol. Ecol. 15, 739-752.

Guindon, S., Gascuel, O., 2003. A simple, fast, and accurate algorithm to estimate large phylogenies by maximum likelihood. Syst. Biol. 52, 696-704.

Guzik, M.T., Cooper, S.J.B., Humphreys, W.F., Austin, A.D., 2009. Fine-scale comparative phylogeography of a sympatric sister species triplet of subterranean diving beetles from a single calcrete aquifer in Western Australia. Mol. Ecol. 18, 3683-3698.

Hall, T.A., 1999. BioEdit: a user-friendly biological sequence alignment editor and analysis program for Windows 95/98/NT. Nucl. Acids Symp. Ser. 41, 95-98.

Hasegawa, M., Kishino, H., Yano, T., 1985. Dating the human-ape split by a molecular clock of mitochondrial DNA. J. Mol. Evol. 22, 160-174. 
Hedin, M., Thomas, S.M., 2010. Molecular systematics of eastern North American Phalangodidae (Arachnida: Opiliones: Laniatores), demonstrating convergent morphological evolution in caves. Mol. Phylogenet. Evol. 54, 107-121.

Hernández, D., 2005. Relaciones evolutivas del género Lucifuga (Ophidiiformes, Bythidae) en Cuba. Master in Science Thesis. University of Havana.

Hudson, R.R., Turelli, M., 2003. Stochasticity overrules the "three-times rule": genetic drift, genetic draft, and coalescence times for nuclear loci versus mitochondrial DNA. Evolution 57, 182-190.

Knowles, L.L., 2001. Did the Pleistocene glaciations promote divergence? Test of explicit refugial models in montane grasshoppers. Mol. Ecol. 10, 691-701.

Lara, A., Ponce de León, J.L., Rodríguez, R., Casane, D., Côté, G., Bernatchez, L., GarcíaMachado, E., 2010. DNA barcoding of Cuban freshwater fishes: evidence for cryptic species and taxonomic conflicts. Mol. Ecol. Resour. 10, 421-430.

Lefébure, T., Douady, C.J., Gouy, M., Trontelj, P., Briolay, J., Gibert, J., 2006 Phylogeography of a subterranean amphipod reveals cryptic diversity and dynamic evolution in extreme environments. Mol. Ecol. 15, 1797-1806.

Lefébure, T., Douady, C.J., Malard, F., Gibert, J., 2007. Testing dispersal and cryptic diversity in a widely distributed groundwater amphipod (Niphargus rhenorhodanensis). Mol. Phylogenet. Evol. 42, 676-686.

Lejeusne, C., Chevaldonné, P., 2006. Brooding crustaceans in a highly fragmented habitat: the genetic structure of Mediterranean marine cave-dwelling mysid populations. Mol. Ecol. 15, 4123-4140.

Leys, R., Watts, C.H.S., Cooper, S.J.B., Humphreys, W.F., 2003. Evolution of subterranean diving beetles (Coleoptera: Dytiscidae: Hydroporini: Bidessini) in the arid zone of Australia. Evolution 57, 2819-2834.

Losos, J.B., Glor, R.E., 2003. Phylogenetic comparative methods and the geography of speciation. Trends Ecol. Evol. 220 (18), 220-227.

Martin, A.P., Bermingham, E., 2000. Regional endemism and cryptic species revealed by molecular and morphological analysis of a widespread species of Neotropica catfish. Proc. Roy. Soc. Lond. B 267, 1135-1141.

Mitchell, R.W., Russell, W.H., Elliot, W.R., 1977. Mexican eyeless characin fishes, genus Astyanax: Environment, distribution, and evolution. Spec. Publ. Mus. Texas Tech Univ. 12, 1-89.

Miya, M., Takeshima, H., Endo, H., Ishiguro, N.B., Inoue, J.G., Mukai, T., Satoh, T.P. Yamaguchi, M., Kawaguchi, A., Mabuchi, K., Shirai, S.M., Nishida, M., 2003. Majo patterns of higher teleostean phylogenies: a new perspective based on 100 complete mitochondrial DNA sequences. Mol. Phylogenet. Evol. 26, 121-138.

Møller, P.R., Schwarzhans, W., Iliffe, T.M., Nielsen, J.G., 2006. Revision of the Bahamian cave-fishes of the genus Lucifuga (Ophidiiformes, Bythitidae), with description of a new species from islands on the Little Bahama Bank. Zootaxa $1223,23-46$.

Moritz, C., Schneider, C.J., Wake, D.B., 1992. Evolutionary relationships within the Ensatina escholtzii complex confirm the ring species interpretation. Syst. Biol. 41, 273-291.

Murphy, N.P., Adams, M., Austin, A.D., 2009. Independent colonization and extensive cryptic speciation of freshwater amphipods in the isolated groundwater springs of Australia's Great Artesian Basin. Mol. Ecol. 18, 109-122.

Nalbant, T.T., 1981. A study of the subterranean species of Lucifuga from Cuba, with the description of Lucifuga simile sp. n. In: Résultats des expéditions biospeologiques cubano-roumaines à Cuba. Acad. Rep. Soc. Romania, vol. 3, pp. $185-190$

Nielsen, J.G., Cohen, D.M., Markle, D.F., Robins, C.R., 1999. Ophidiiform Fishes of the World. FAO Species Catalogue, vol. 18, pp. I-XI + 1-178.

Nuevo Atlas Nacional de Cuba, 1989. Edited by: Instituto de Geografía y el Instituto Cubano de Geodesia y Cartografía. Ciudad de la Habana. Academia de Ciencias de Cuba.

Nuñez-Jiménez, A., 1967. Clasificación genética de las cuevas de Cuba. Academia de Ciencias de Cuba, $224 \mathrm{p}$.

Nuñez-Jiménez, A., Viña, N., Acevedo, M., Mateo, J., Iturralde-Vinent, M., Graña, A., 1984. Cuevas y Carsos. Editorial Científico-Técnica. La Habana.

Page, T.J., Humphreys, W.F., Hughes, J.M., 2008. Shrimps down under: evolutionary relationships of subterranean crustaceans from Western Australia (Decapoda: Atyidae: Stygiocaris). PLoS One 3 (2), e1618.

Pagel, M., Meade, A., 2006. BayesTraits Version 1.0, Distributed over the Internet Reading, UK. <http://www.evolution.rdg.ac.uk/BayesTraits.html> (revised 10.02.10).

Pagel, M., Meader, A., Barker, D., 2004. Bayesian estimation of ancestral character states on phylogenies. Syst. Biol. 53, 673-684.

Pérez, J.E., Moodie, G.E., 1993. Genetic variation in a cave-dwelling Venezuelan catfish. Zoología (Acta Científica Venezolana) 44, 28-31.

Philippe, H., Snell, E.A., Bapteste, E., Lopez, P., Holland, P.W.H., Casane, D., 2004 Phylogenomics of Eukaryotes: impact of missing data on large alignments. Mol. Biol. Evol. 21, 1740-1752.

Poey, F., 1858. Memorias sobre la Historia Natural de la Isla de Cuba. Imprenta Viuda de Barcina, La Habana.

Poey, F., 2000. Ictiología Cubana. Volumen II. Casa de Altos Estudios Don Fernándo Ortiz. Universidad de La Habana.
Posada, D., 2008. JModelTest: phylogenetic model averaging. Mol. Biol. Evol. 25, 1253-1256.

Posada, D., Crandall, K.A., Templeton, A.R., 2000. GEODIS: a program for the cladistic nested analysis of genetic haplotypes. Mol. Ecol. 9, 487-488.

Romero, A., 2001. Scientists prefer them blind: the history of hypogean fish research. Environ. Biol. Fishes 62, 43-71.

Ronquist, F., Huelsenbeck, J.P., 2003. MrBayes 3: Bayesian phylogenetic inference under mixed models. Bioinformatics 19, 1572-1574.

Schwarz, G., 1978. Estimating the dimension of a model. Ann. Stat. 6, 461-464.

Sites, J.W., Crandall, K., 1997. Testing species boundaries in biodiversity studies. Conserv. Biol. 11, 1289-1297.

Sites, J.W.J., Marshall, J.C., 2003. Delimiting species: a Renaissance issue in systematic biology. Trends Ecol. Evol. 18, 462-470.

Slatkin, M., Maddison, W.P., 1989. A cladistic measure of gene flow inferred from the phylogenies of alleles. Genetics 123, 603-613.

Strecker, U., Bernatchez, L., Wilkens, H., 2003. Genetic divergence between cave and surface populations of Astyanax in Mexico (Characidae, Teleostei). Mol. Ecol. 12, 699-710.

Strecker, U., Faundez, V.H., Wilkens, H., 2004. Phylogeography of surface and cave Astyanax (Teleostei) from Central and North America based on cytochrome b sequence data. Mol. Phylogenet. Evol. 33, 469-481.

Tamura, K., Nei, M., 1993. Estimation of the number of nucleotide substitutions in the control region of the mitochondrial DNA of the humans and chimpanzees. Mol. Biol. Evol. 10, 512-526.

Tamura, K., Dudley, J., Nei, M., Kumar, S., 2007. MEGA4: molecular evolutionary genetics analysis (MEGA) software version 4.0. Mol. Biol. Evol. 24, 1596-1599.

Templeton, A.R., 1980. The theory of speciation via the founder principle. Genetics 94, 1011-1038.

Templeton, A.R., 2009. Statistical hypothesis testing in intraspecific phylogeography: nested clade phylogeographical analysis vs. approximate Bayesian computation. Mol. Ecol. 18, 319-331.

Templeton, A.R., Sing, C.F., 1993. A cladistic analysis of phenotypic associations with haplotypes inferred from restriction endonuclease mapping. IV. Nested analyses with cladogram uncertainty and recombination. Genetics 134, 659-669.

Templeton, A.R., Boerwinkle, E., Sing, C.F., 1987. A cladistic analysis of phenotypic associations with haplotypes inferred from restriction endonuclease mapping. I Basic theory and an analysis of Alcohol Dehydrogenase activity in Drosophila. Genetics 117, 343-351.

Thompson, J.D., Higgins, D.G., Gibson, T.J., 1994. Clustal W: improving the sensitivity of progressive multiple sequence alignment through sequence weighting, position-specific gap penalties and weight matrix choice. Nucl. Acid Res. 22, 4673-4680.

Trontelj, P., Douady, C.J., Fišer, C., Gibert, J., Goricški, Š., Lefébure, T., Sket, B., Zakšek, V., 2009. A molecular test for cryptic diversity in ground water: how large are the ranges of macro-stygobionts? Freshwater Biol. 54, 727-744.

Vergara, R., 1980. Estudio filogenético de los peces ciegos del género Lucifuga (Pisces: Ophidiidae). I. Sistemática filogenética. Rev. CENIC 11, 311-323.

Vergara, R., 1981. Estudio filogenético de los peces ciegos del género Lucifuga (Pisces: Ophidiidae). II. Bibliografía filogenética. Rev. Cienc. Biol. 12, 99-107.

Verovnik, R., Sket, B., Trontelj, P., 2005. The colonization of Europe by the freshwater crustacean Asellus aquaticus (Crustacea: Isopoda) proceeded from ancient refugia and was directed by habitat connectivity. Mol. Ecol. 14, 4355-4369.

Wiens, J.J., 2006. Missing data and the design of phylogenetic analyses. J. Biomed. Inform. 39, 34-42.

Wiens, J.J., Servedio, M.R., 2000. Species delimitation in systematics: inferring diagnostic differences between species. Proc. Roy. Soc. Lond. B 267, 631-636.

Wiens, J.J., Chippindale, P.T., Hillis, D.M., 2003. When are phylogenetic analyses misled by convergence? A case study in Texas cave salamanders. Syst. Biol. 52, 501-514.

Wilkens, H., 1988. Evolution and genetics of epigean and cave Astyanax fasciatus (Characidae, Pisces). Support for the neutral mutation theory. In: Hecht, M.K., Wallace, B. (Eds.), Evolutionary Biology, vol. 23. Plenum Publishing Corporation, New York, London, pp. 271-367.

Wilkens, H., Strecker, U., 2003. Convergent evolution of the cavefish Astyanax (Characidae, Teleostei): genetic evidence from eye and pigment reduction. Biol. J. Linnean Soc. 80 (4), 545-554.

Xiao, H., Chen, S.-Y., Liu, Z.-M., Zhang, R.-D., Li, W.X., Zan, R.-G., Zhang, Y.-P., 2005. Molecular phylogeny of Sinocyclocheilus (Cypriniformes: Cyprinidae) inferred from mitochondrial DNA sequences. Mol. Phylogenet. Evol. 36, 67-77.

Zakšek, V., Sket, B., Trontelj, P., 2007. Phylogeny of the cave shrimp Troglocaris: Evidence of a young connection between Balkans and Caucasus. Mol Phylogenet. Evol. 42, 223-235.

Zakšek, V., Sket, B., Gottstein, S., Franjevicp, D., Trontelj, P., 2009. The limits of cryptic diversity in groundwater: phylogeography of the cave shrimp Troglocaris anophthalmus (Crustacea: Decapoda: Atyidae). Mol. Ecol. 18, 931946. 